\title{
ASSESSMENT OF OCCUPATIONAL HEAT STRESS RISK AMONG AGRICULTURE WORKERS IN POLAND AND BULGARIA
}

\author{
Krzysztof Blażejczyk¹, Valentin Kazandjiev², Marek Degórski', Peter Dimitrov² \\ ${ }^{1}$ Institute of Geography and Spatial Organization \\ Polish Academy of Sciences \\ Twarda 51/55, 00-818 Warsaw, Poland \\ k.blaz@twarda.pan.pl,m.degor@twarda.pan.pl \\ ${ }^{2}$ National Institute of Meteorology and Hydrology \\ Bulgarian Academy of Sciences \\ Sofia, 1784, 66 Tsarigradsko shausse, Bulgaria \\ valentin.kazandjiev@meteo.bg,dimitrov_pn@yahoo.com
}

\begin{abstract}
Agriculture is a sector of the national economy strongly influenced by climatic conditions. A majority of jobs in agriculture are still performed outdoors, under various weather conditions. Several meteorological situations can lead to severe disturbances in the organism of agricultural workers, with high temperature, intensive insolation and elevated air humidity proving especially dangerous, as such weather conditions can lead to overheating and dehydration of the body. The work presented here compares biothermal conditions in Poland and Bulgaria from the point of view of occupational health. To this end, use was made of several indices assessing heat stress in human beings, namely: Wet Bulb Globe Temperature (WBGT), HUMIDEX, Water Loss (SW), Universal Thermal Climate Index (UTCI) and Physiological Subjective Temperature (PST). When account was taken of the occurrence of heat extremes as defined by these indices, it proved possible to distinguish categories of health risk regarded as small, increased or great. Comparison of the two agricultural regions reveals significantly more severe heat stress in Bulgaria than in Poland, in terms of both the frequency of heat-stress episodes and the number of hours (daily and monthly) associated with heat stress. This ensures that dangerous conditions for agriculture workers are primarily present in Bulgaria, rather than in Poland.
\end{abstract}

Keywords: agriculture, Bulgaria, heat stress, occupational health, Poland.

\section{Introduction}

Occupational heat stress is a well-known hazard in outdoor workplaces exposed to strong sunlight and elevated environmental temperatures, such as those associated with work in agriculture, forestry, quarrying, roadbuilding and construction (Nag \& Nag 2009). The health risks here are reflect an increase in core body temperature and/or excessive sweat loss and dehydration, and these are in fact very well- known consequences of exposure to heat (Parsons 2003). 
During the warm part of the year, the overall environmental conditions as regards heat can assume levels that give rise to occupational health risks and can reduce worker productivity in any outdoor workplaces (Kjellstrom et al. 2009). In central and southern European countries in particular heat may represent a significant warm-season hazard, especially during heatwaves (Adam-Poupart et al. 2012).

Table 1 provides definitions of three key concepts related to heat hazards (namely heat exposure, heat stress and heat strain) that need to be quantified to improve occupational health and safety research. Several indicators of occupational heat exposure incorporating physical properties of the ambient environment have been developed. The indices used most frequently are WBGT (Wet Bulb Globe Temperature), ET (Effective Temperature), CET (Corrected Effective Temperature) and Humidex (Epstein \& Moran 2006), as well as the recently-developed UTCI (Universal Thermal Climate Index) (Błażejczyk et al. 2012, 2014, Bröde et al. 2012).

Table 1. Heat hazard definitions and the means of quantification

\begin{tabular}{|l|l|}
\hline $\begin{array}{c}\text { Heat hazard } \\
\text { measure }\end{array}$ & \multicolumn{1}{c|}{ Means of quantification: } \\
\hline Heat exposure & $\begin{array}{l}\text { The actual thermal environmental conditions quantified in a way that is relevant to the likely } \\
\text { heat stress. This variable is calculated using the climatic data (weather-station data or specially } \\
\text { measured data). The heat exposure of relevance depends on air temperature, humidity, air } \\
\text { movement and solar radiation. All of these factors are modified significantly by local features } \\
\text { of the surroundings (Błażejczyk 2011, Błażejczyk \& Kunert 2006). Exposure can be reduced by } \\
\text { shades, fans, air conditioning or other cooling systems. }\end{array}$ \\
\hline Heat stress & $\begin{array}{l}\text { The heat burden on individual physiology and capacity as regards human performance is } \\
\text { determined by the level and duration of "heat exposure", the intensity of physical activity } \\
\text { (metabolic rate), and the clothing worn. Heat stress can be reduced by using suitable clothing } \\
\text { or reducing metabolic rate (which means working less intensively and taking more rest breaks, } \\
\text { in the case of working people). Increased sweating and a limited work regime to prevent core } \\
\text { body temperature from increasing are normal physiological reactions to heat stress. }\end{array}$ \\
\hline Heat strain & $\begin{array}{l}\text { A limited increase in core body temperature and subsequent sweating are part of the physi- } \\
\text { ological reaction to heat stress that encompasses low and reversible physiological strain. At } \\
\text { higher levels of heat stress the physiological strain on the human body is great enough to create } \\
\text { excessive and irreversible heat strain symptoms eventually leading to hyperthermia, sunstroke } \\
\text { or heat exhaustion. In extreme cases severe heat stroke and even death may occur. }\end{array}$ \\
\hline
\end{tabular}

Outdoor agriculture is a particularly high-risk industry with an occupational mortality rate 20 times higher than all industries combined in the USA (CDC 2008). There are several reasons for this, e.g. incentives to increase hourly work output, a lack of shade structures and breaks during the working day, and inadequate water availability and intake (Leibman \& Augustave 2010). However, heat-related stress and illness, especially in regard to agricultural workers' health and safety, are adequately addressed by the research and outreach community (Jackson \& Rosenberg 2010).

The risk of an organism overheating is the effect of human-environment heat exchange (Fiala et al. 2012). In hot conditions, the heat balance is mainly regulated by increased evaporation of sweat from the body, with evaporative heat loss constituting $75 \%$ of total heat losses. Hazardous health disorders can arise if dehydration takes place. Water loss of about $2 \%$ of body weight produces only thirst and heat fatigue, while a greater loss of water denotes dehydration symptoms that are more dangerous. At $4 \%$ dehydration, people may additionally experience a dry mouth. At subsequent levels of dehydration the following symptoms appear: $6 \%$ - increased heart rate and body temperature; $8 \%$ - swollen tongue, difficulties in speaking, reduced physical and mental performance; $12 \%$ - loss of body weight, with recovery only possible after fluid infusion. Finally, 14\% dehydration leads to 
rapid temperature increase and death. In certain conditions the physiological regulation of body temperature is insufficient to maintain thermal equilibrium or can lead to major health disturbances. In general, skin eruptions, heat fatigue, heat cramps, heat syncope, heat exhaustion and heat stroke are classic heat-related diseases. Essentially, most of these results from various degrees of thermoregulatory system failure (Heat-waves: risks and responses 2004).

The aim of the present paper is to assess the risk of heat stress caused by extreme heat exposure among those working in intensive agriculture in Poland and Bulgaria, during the warm period of the year (April-October).

\section{Methods and materials}

The assessment of occupational heat-stress risk made use of an analysis of hourly meteorological data for a typical year. These were extracted from the METEONORM 7.0 database and software package for two stations each in Poland (Warsaw and Kalisz) and Bulgaria (Pleven and Plovdiv). For the calculation of a typical year's values, METEONORM draws on meteorological observations of air temperature, air vapour pressure and wind speed for the period 2000-2009, or else 1985-2005 in the case of solar radiation.

To evaluate the heat-stress risk among farmworkers, use was made of five indices used in occupational health assessment. The first, Wet-Bulb Globe Temperature (WBGT, ${ }^{\circ} \mathrm{C}$ ), is the most widely-used heat stress index (ISO 7243). It was developed in the US Navy as part of a study on heat-related injuries during military training (Yaglou \& Minard 1957). The WBGT index involves weighted values of the dry-bulb temperature $\left(\mathrm{Ta},{ }^{\circ} \mathrm{C}\right)$, natural (un-aspirated) wet-bulb temperature $\left(\mathrm{T}_{\text {nw }},{ }^{\circ} \mathrm{C}\right)$ and black-globe temperature $\left(\mathrm{T}_{\text {globe }},{ }^{\circ} \mathrm{C}\right)$ in the following manner:

$$
\mathrm{WBGT}=0.7 \cdot \mathrm{T}_{\mathrm{nw}}+0.1 \cdot \mathrm{Ta}+0.2 \cdot \mathrm{T}_{\text {globe }}
$$

In the present study, the $\mathrm{T}_{\mathrm{nw}}$ and $\mathrm{T}_{\text {globe }}$ components were assessed using an approach proposed by Błażejczyk et al. (2014). In line with recommendations of the American Conference of Government Industrial Hygienists (ACGIH), a WBGT value of $28^{\circ} \mathrm{C}$ was applied as the "permissible heat exposure threshold limit".

The second index is HUMIXED $\left({ }^{\circ} \mathrm{C}\right)$, a Canadian innovation in heat-stress assessment, first used in 1965. The index has been revised by Masterson and Richardson (1979), and describes how hot, humid weather is experienced by an average person. It combines air temperature $\left(\mathrm{Ta},{ }^{\circ} \mathrm{C}\right)$ and air vapour pressure (vp, $\mathrm{hPa}$ ) into one number reflecting the perceived temperature:

$$
\text { HUMIDEX }=\mathrm{Ta}+0.5555 \cdot(\mathrm{vp}-10)
$$

In line with the assessment scale developed by the Canadian Meteorological Service, a HUMIDEX value of $40^{\circ} \mathrm{C}$ was taken as a limit of discomfort at which all unnecessary activity should be curtailed.

The third index is water loss due to sweat secretion ( $\mathrm{SW}, \mathrm{ml} /$ hour). $\mathrm{SW}$ is calculated on the basis of potential values for evaporative heat loss (Epot, ml/hour).

$$
\mathrm{SW}=-2.6 \cdot \text { Epot }
$$


Epot is derived from man-environment heat exchange model MENEX_2005 (Błażejczyk \& Kunert 2011), taking into account a 5\% level of relative air humidity. In line with ISO 7933, an SW value of $520 \mathrm{ml} /$ hour was taken as a warning limit where risk of dehydration is concerned.

The fourth index applied in the research described here was Physiological Subjective Temperature $\left(\mathrm{PST},{ }^{\circ} \mathrm{C}\right)$ - which represents the subjective experience of a thermal environment by a person after 20 minutes' adaptation to ambient conditions. The index is derived from the MENEX_2005 human heat balance model (Błażejczyk 2006b). The thermal impacts exerted by the environment are expressed in terms of the temperature surrounding the skin surface. In line with the assessment scale, a PST value of $34^{\circ} \mathrm{C}$ was taken as a threshold for hot thermal sensation of persons working outdoors under a load of $135 \mathrm{~W} / \mathrm{m}^{2}$.

The fifth measure of heat stress is the most recently developed, the Universal Thermal Climate Index (UTCI, ${ }^{\circ} \mathrm{C}$ ), which is defined as the equivalent ambient temperature of a reference environment that evokes the same physiological response from a person as in the real environment (Błażejczyk et al. 2010, Bröde et al. 2012). The index is a measure of the heat stress caused by ambient conditions that a person experiences. The UTCI derives from Fiala's multi-node model of human heat transfer and temperature regulation (Fiala et al. 2012), and has found repeated application in occupational health research (Kampmann et al. 2012, Bröde et al. 2013, Błażejczyk et al. 2014). In the research described here, the UTCI was calculated using a regression model (Bröde et al. 2012). Under the assessment scale, the UTCI value of $32^{\circ} \mathrm{C}$ was taken as the threshold for strong heat stress manifested by intensive evaporation and increasing body core temperature.

Three of the measures used (WBGT, SW and UTCI) are of an objective nature and provide current information on the physiological reactions of the human organism to ambient stimuli. Equally, two measures (HUMIDEX and PST) provide information on what persons working out of doors feel subjectively.

All the measures of occupational heat stress were calculated using the BioKlima 2.6 software package ${ }^{1}$. Calculations of the heat-stress measures were made for every hour of a typical year, with data for the April-October period used in the analysis. In the case of both countries, these months are typical for intensive farm work in open-air conditions (such as planting, cultivating and harvesting).

With a view to the health risks facing the agriculture workers being assessed, three categories of heat stress were defined. If just one of the five measures was associated with a value above the threshold, then the health risk was categorised as small. In turn, if two heat-stress measures were reported to be elevated then the health risk was categorised as increased. However, if three or more measures were characterised by values above the thresholds then the cases involved were categorised as posing a great risk to health. The occurrence of such health-risk categories was defined for each hour of the analysed period, before the number of health-risk episodes (EN), number of hours characterised by the various categories of health risk $(\mathrm{HN})$, and the average length of each episode (EL, in hours) were calculated and analysed.

\section{Results}

Analysis of the selected measures of occupational heat stress revealed significant differences between the regions studied, in the sense that Poland reported values for all the used indices used that were

1 http://www.igipz.pan.pl/Bioklima-zgik.html 
lower than those characterising Bulgaria. However, this is mainly true of average or maximum values for the indices, given that minimum values are found to be relatively similar in the two countries.

At the Polish stations, the mean WBGT values range from about $5^{\circ} \mathrm{C}$ in April and October to about 16 in July and August. In Bulgaria, in turn, mean values for the index rise from about $8^{\circ} \mathrm{C}$ in April to $19-20^{\circ} \mathrm{C}$ in July and August. Maximum WBGT values are very important from the occupational health point of view, and in Poland, these are not shown to reach the permissible heat-exposure threshold limit (of $28^{\circ} \mathrm{C}$ ) in any month. In contrast, in Bulgaria this limit is exceeded during the three summer months of June, July and August (Fig. 1).

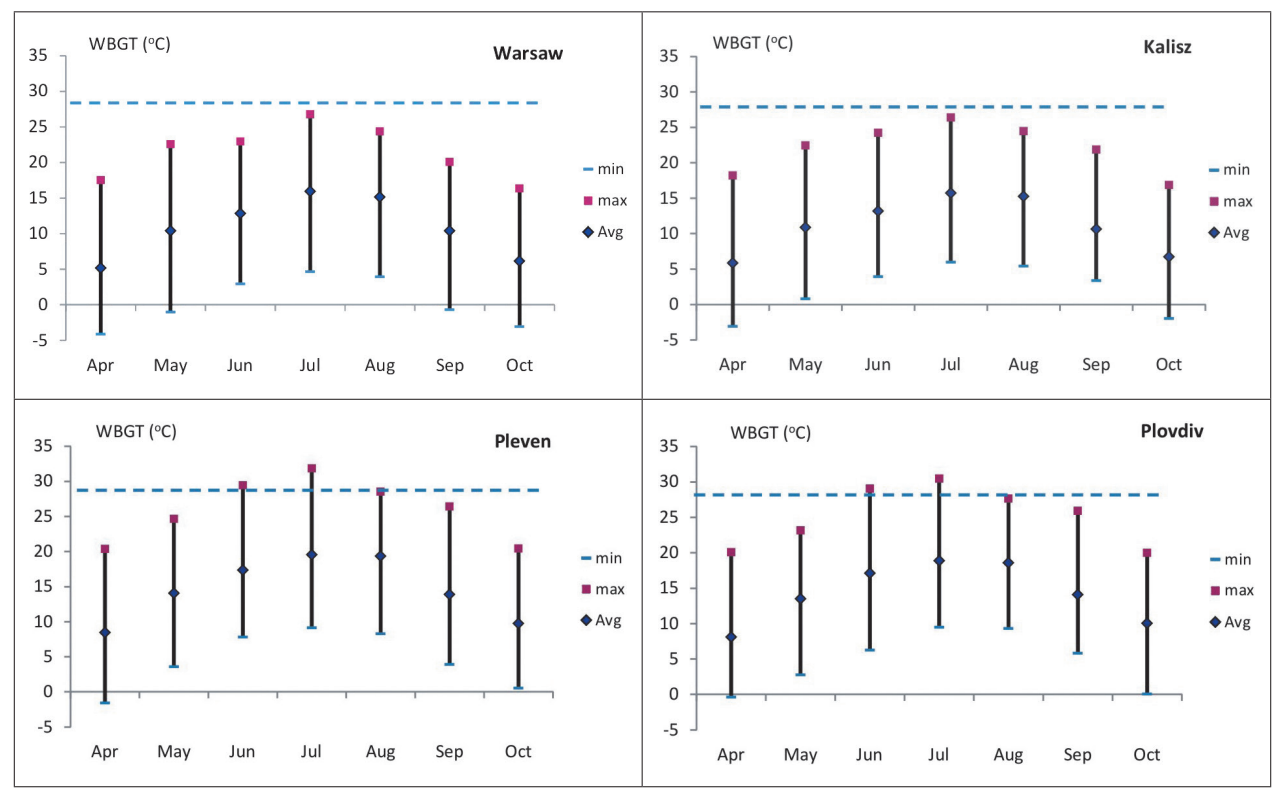

Figure 1. Mean (Avg), maximum (max) and minimum (min) monthly values for Wet Bulb Globe Temperature (WBGT) at the studied Polish and Bulgarian stations; dotted lines indicate the threshold limit for WBGT

The Universal Thermal Climate Index is the most complex indicator of both cold and heat stress in human beings out of doors, in circumstances of moderate physical activity. Mean monthly UTCI in Poland changes from about $2-3^{\circ} \mathrm{C}$ in April and October to $17-18^{\circ} \mathrm{C}$ in July. In Bulgaria, corresponding values for the index range from $8-9^{\circ} \mathrm{C}$ in April to $23-24^{\circ} \mathrm{C}$ in July and August.

UTCI values $>32^{\circ} \mathrm{C}$ are in turn taken to indicate strong heat stress for people working outdoors. At Polish stations, this UTCI threshold can be exceeded in four months of the year (May-August), reaching $34-35^{\circ} \mathrm{C}$ in July. In contrast, in Bulgaria, this limit for strong heat stress is capable of being exceeded across the whole April-September period. Moreover, from May through to September meteorological conditions in Bulgaria are even capable of generating very strong heat stress (Fig. 2). 


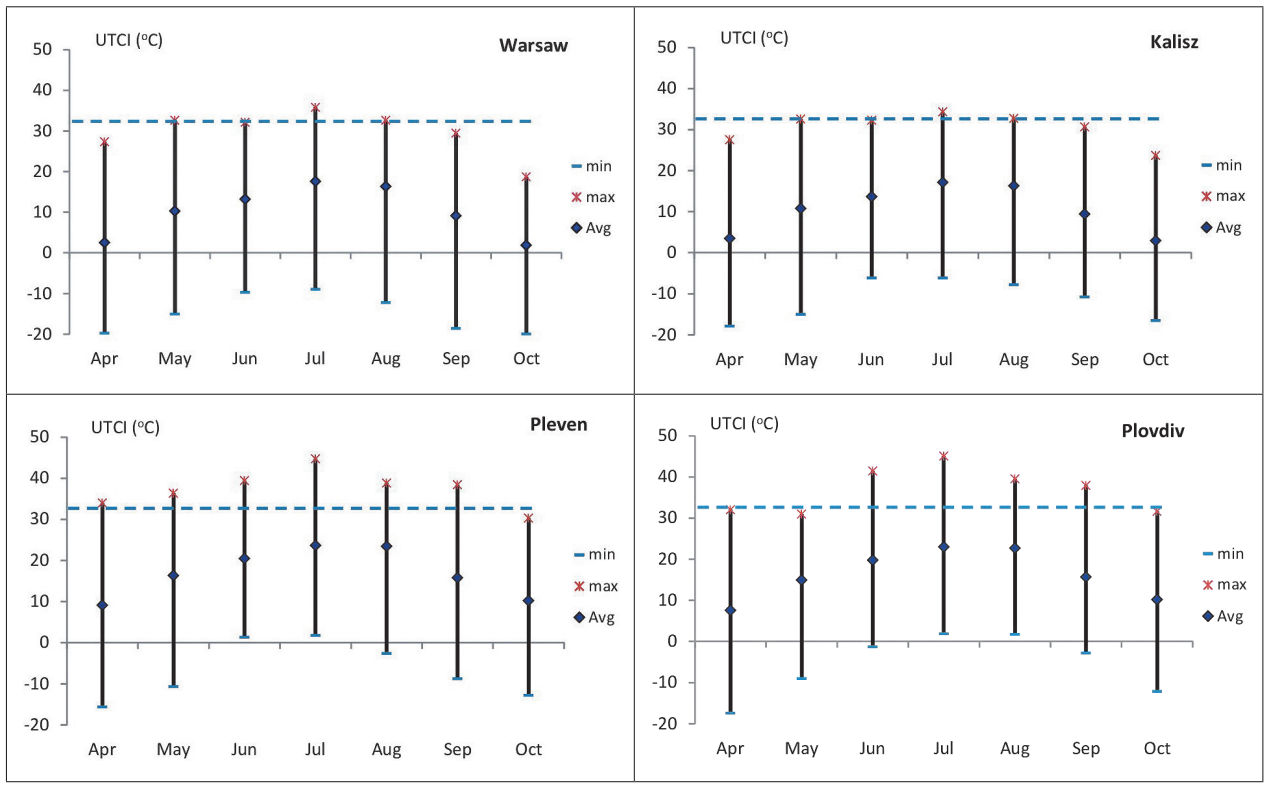

Figure 2. Mean (Avg), maximum (max) and minimum (min) monthly values for the Universal Thermal Climate Index (UTCI) at the Polish and Bulgarian meteorological stations studied; dotted lines mark the threshold for so-called strong heat stress

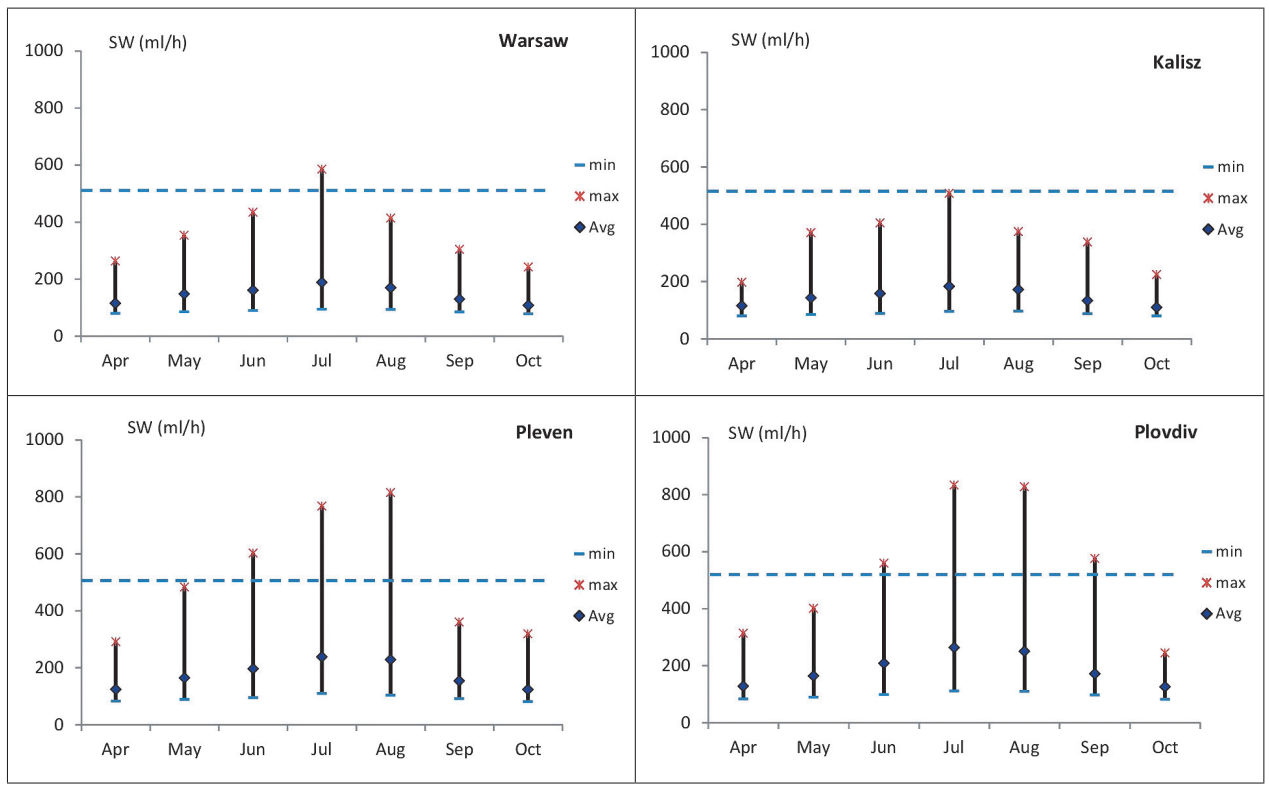

Figure 3. Mean (Avg), maximum (max) and minimum (min) monthly values for the water loss index (SW) at the studied Polish and Bulgarian stations; dotted lines indicate the warning limit where dehydration is concerned 
One of the greatest risks to health related to heat stress is that of dehydration. Water loss due to sweating of more than $520 \mathrm{ml} /$ hour is considered a warning in the case of working persons. While this limit can only be reached occasionally in July in the case of Poland, in Bulgaria such conditions can occur at any time in the June-September period (Fig. 3).

HUMIDEX is an index used frequently in tropical and subtropical countries, with a view to people outdoors' subjective experiences of hygrothermal conditions being assessed. The HUMIDEX limit of $40^{\circ} \mathrm{C}$, defined as "Discomfort. All unnecessary activities should be curtailed" is not reached at all at Polish stations. However, in Bulgaria, such conditions are to be noted during 3 summer months (JJA), with $45^{\circ} \mathrm{C}$ capable of being attained in July (Fig. 4).

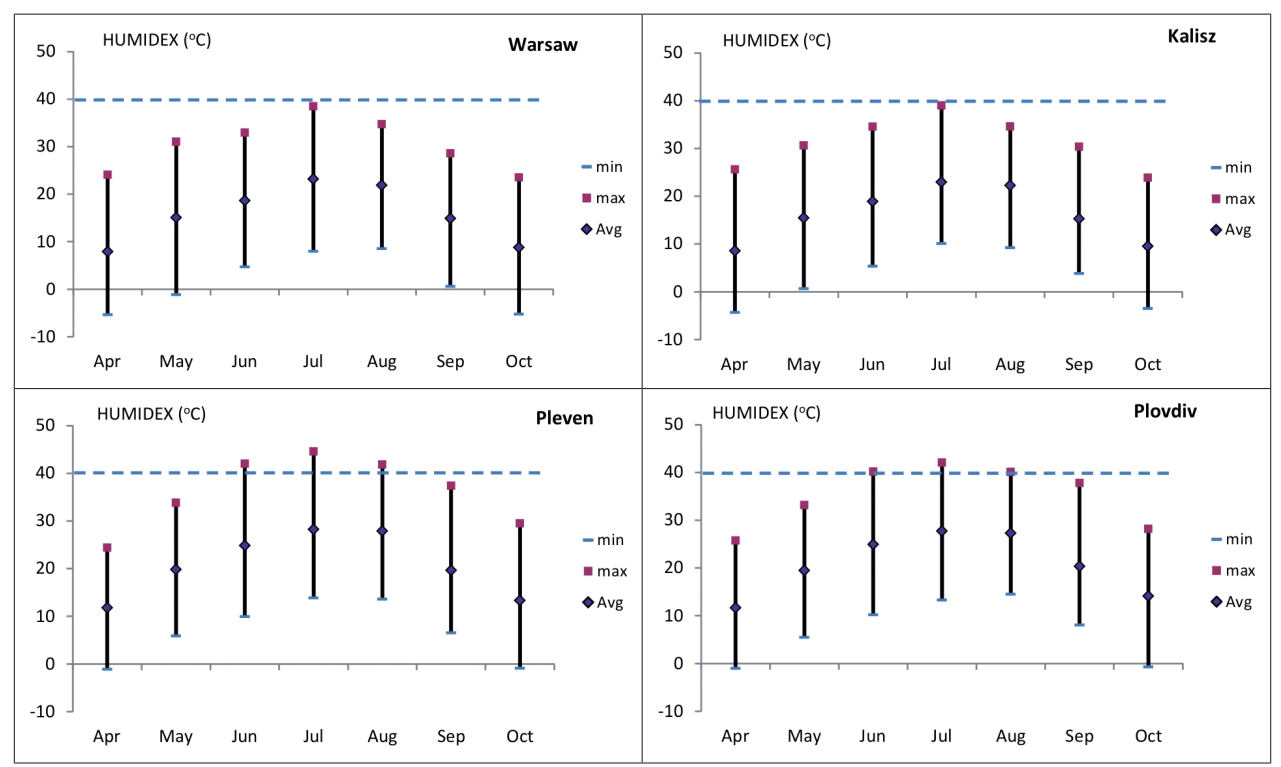

Figure 4. Mean (Avg), maximum (max) and minimum (min) monthly values for the HUMIDEX index at the Polish and Bulgarian stations studied; dotted lines indicate the threshold limit for HUMIDEX

The PST index offers an insight into the thermal experiences of those working outdoors with an activity of $135 \mathrm{~W} / \mathrm{m}^{2}$. A value of $34^{\circ} \mathrm{C}$ indicates thermal sensations at the hot level at least. In Poland, such meteorological conditions occur from May through to September, with the PST maximum capable of reaching $42^{\circ} \mathrm{C}$ in July and August. In contrast, in Bulgaria the applied PST limit is exceeded during all of the months considered. Indeed, from June through to September, maximum PST values for the country can reach $58-59^{\circ} \mathrm{C}$, which indicates the thermal sensation of sweltering (Fig. 5). 


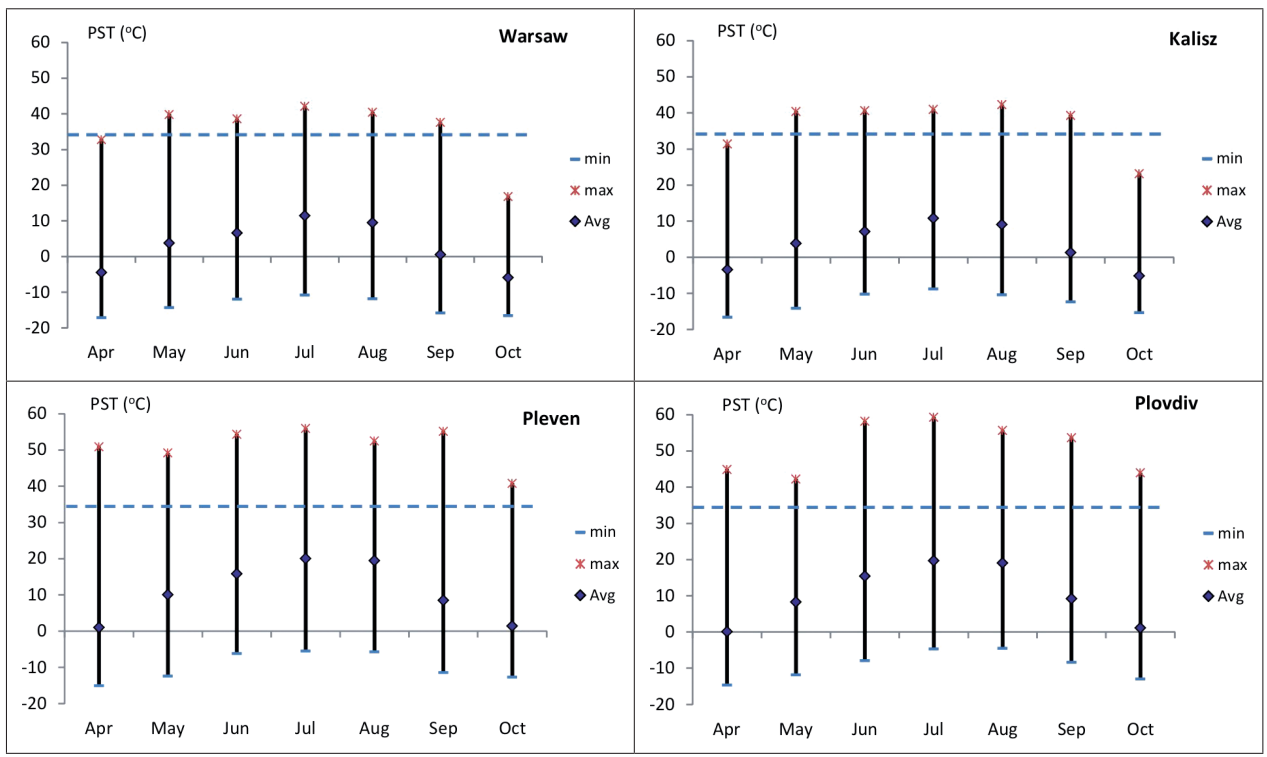

Figure 5. Mean (Avg), maximum (max) and minimum (min) monthly values for Physiological Subjective Temperature (PST) at the Polish and Bulgarian stations studied; dotted lines indicate the threshold limit for the thermal sensation "hot"

This overview of reported heat-stress indices makes the differences between the Polish and Bulgarian bioclimates quite clear. However, any detailed assessment of occupational heat-stress risk should consider, not only the extremes reached in the case of the indices studied, but also the frequency of occurrence of stressful conditions. To this end, three indicators were analysed: the number of health-risk episodes (EN), the number of hours during which various health-risk categories apply (HN), and the mean length of each episode of the above kind (EL).

In Poland, episodes of any of the kinds of health risk can arise through the May-September period, albeit with a frequency of occurrence of about 5 episodes in May and September, as opposed to some 10-14 in July. In Bulgaria, episodes of health risk of this kind are to be recorded in all of the months studied, with EN values rising from about 4 in April (obviously the second half of the month) and October (its first 10-day period) to some 25-28 in the case of July and August. This is to say that, in the latter months, health-risk episodes are present almost every day (Fig. 6). The EN comparison shows that heat stress incidences capable of causing a risk to health during the summer season are 2.5 times as regular in Bulgaria as in Poland. 


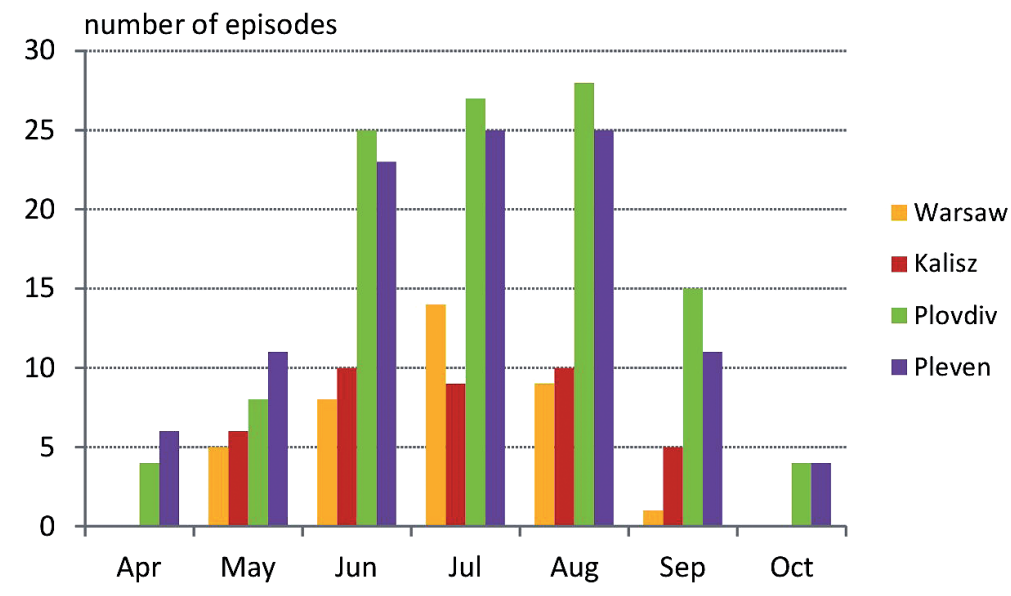

Figure 6. The number of health-risk episodes of all kinds during particular months at the studied Polish and Bulgarian stations

The number of hours associated with a health risk was in turn calculated to assess the lengths of time over which conditions imposing stress persisted. The analysis shows that total number of hours varies significantly with station and month. In Poland, the greatest HN (65) is observed in Warsaw in July, while Kalisz reaches 44-45 in June and July. In other months, HN is in the range from 3 (in September) to 33 (in August). In Bulgaria, the total for health-risk hours is found to significantly higher than in Poland. The highest values (of 165-175 hours per month) are to be observed in July and August. In contrast, in April and October HN reaches just 6-10 hours (Fig. 7). The HN comparison shows that, during the summer season, heat-stress conditions capable of giving rise to a health risk persist for 3.5 times as long a period in Bulgaria as in Poland.

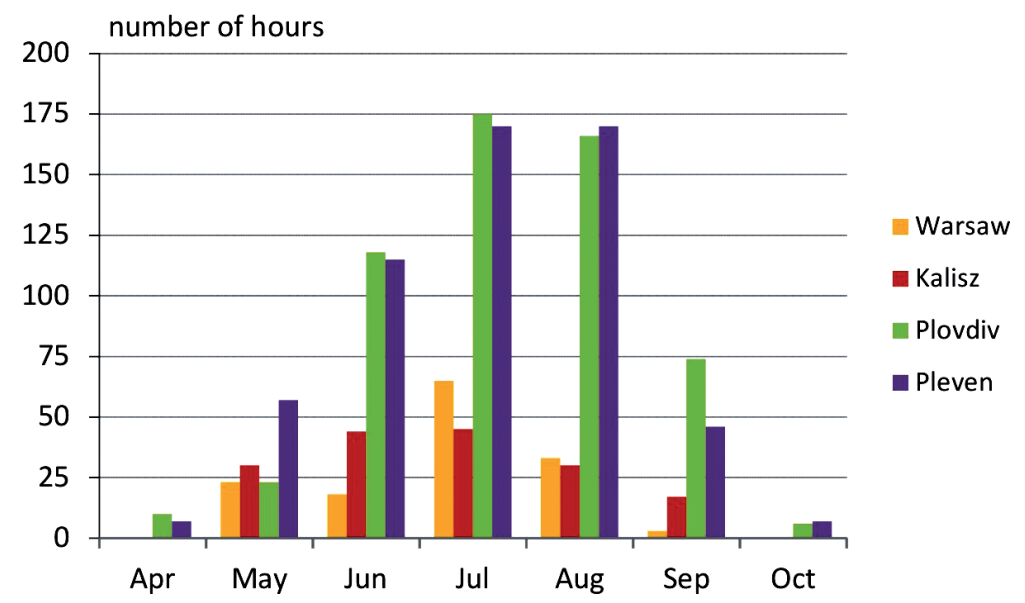

Figure 7. Number of hours of health risks of different kinds in particular months, in the cases of the Polish and Bulgarian stations studied 
Regional differences are also observed when it comes to comparisons of the mean length of an individual episode associated with a health risk (EL). In Poland, EL lasts about 2-3 hours in June, as opposed to almost 5 hours in May and July. In Bulgaria, EL varies from 1-2 hours in April and October to almost 7 hours in July and August (though on particular summer days, health-risk conditions can even persist for 13-14 hours at the Bulgarian stations). However, in comparing EL values for the analysed warm period (April-October), it can be seen that the mean duration of health-risk episodes is in fact relatively similar in the two countries (Fig. 8).

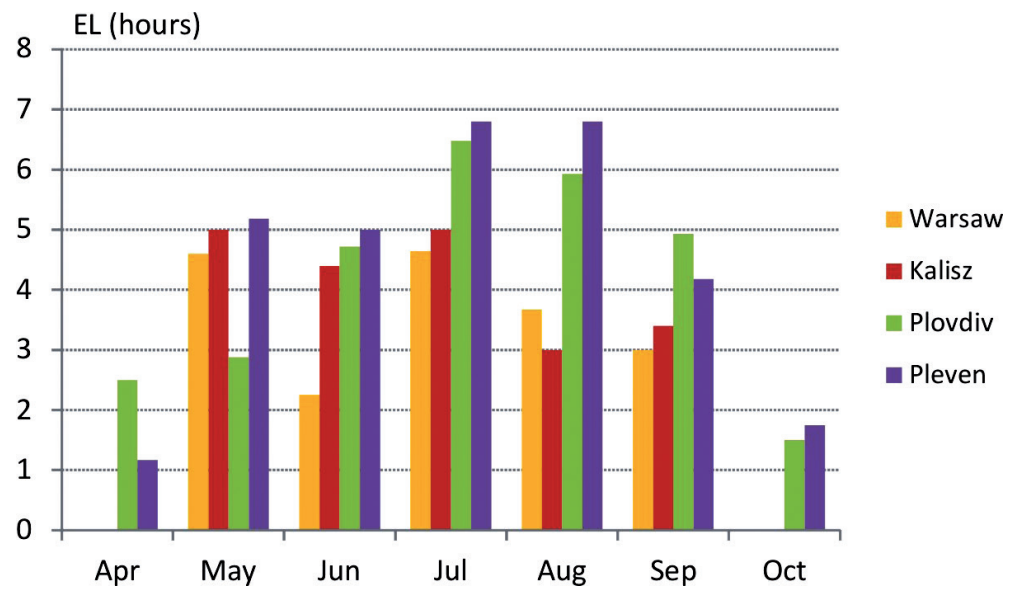

Figure 8. Mean lengths of health-risk episodes in particular months at the studied Polish and Bulgarian stations

The final analysis was concerned with the frequency of occurrence of episodes and hours characterised by increased $(\mathrm{ENi}, \mathrm{HNi})$ or great $(\mathrm{ENg}, \mathrm{HNg}$ ) risk of a human body overheating, as well as the mean length of the respective episodes. An elevated health risk only occurs relatively rarely in Poland. ENi rises from 1 in May to 3 in June, July and August. April, September and October are in turn months in Poland in which the risk of the organism overheating is not increased. By contrast, in Bulgaria, an increased health risk is to be observed all the way from April through to September. The number of episodes (ENi) varies from 1 in the late spring to 10-12 in the summer months. Where the episodes of great health risk $(\mathrm{ENg})$ were concerned, a confinement to the Bulgarian stations was noted, with frequencies of occurrence being once or twice in June, and as many as 7-8 times in July and August. Consequently, the numbers of hours associated with increased ( $\mathrm{HNi})$ and great $(\mathrm{HNg})$ health risks differ in the cases of the countries compared. In Poland, maximum HNi values can be recorded in July (22-24); while in Bulgaria the July and August HNi is above 70 hours per month. $\mathrm{HNg}$ in Bulgaria can reach 56-65 hours, in June and August (Tab. 2).

While the numbers of episodes and hours of increased and great health risk differ significantly between countries, the mean lengths of individual episodes are seen to be similar. ELi values in Poland and Bulgaria are usually of 6-8 hours, and are only lower (2-3 hours) occasionally. When the lengths of increased and great risk episodes in Bulgaria are compared, ELg is seen to be higher than ELi. In July, the mean length of great-risk episodes can be 9.5 hours (Tab. 1). This shows that in both Bulgaria and Poland the meteorological conditions giving rise to increased or great risks of the organism overheating are stable and longlasting, given that they cover the entire working day, from 9-10 a.m. till 6-7 p.m. 
Table 2. A characterisation of the increased and great health risks caused by the heat stress occurring at the Polish and Bulgarian stations studied

\begin{tabular}{|c|c|c|c|c|c|c|c|c|}
\hline & Warsaw & Kalisz & Plovdiv & Pleven & Warsaw & Kalisz & Plovdiv & Pleven \\
\hline & \multicolumn{4}{|c|}{$\begin{array}{l}\text { number of episodes featuring increased risk } \\
\text { (ENi) }\end{array}$} & \multicolumn{4}{|c|}{$\begin{array}{c}\text { number of episodes featuring great risk } \\
\text { (ENg) }\end{array}$} \\
\hline April & . & . & . & 1 & . & . & . & . \\
\hline May & . & 1 & . & 1 & . & . & . & . \\
\hline June & . & 3 & 6 & 10 & . & . & 1 & 2 \\
\hline July & 3 & 3 & 12 & 10 & . & . & 7 & 6 \\
\hline August & 3 & 2 & 10 & 11 & . & . & 5 & 8 \\
\hline September & . & . & 5 & 3 & . & . & . & . \\
\hline \multirow[t]{2}{*}{ October } & . & . & . & . & . & . & . & . \\
\hline & \multicolumn{4}{|c|}{ number of hours of increased risk (HNi) } & \multicolumn{4}{|c|}{ number of hours of great risk ( $\mathrm{HNg})$} \\
\hline April & . & . & . & 2 & . & . & . & . \\
\hline May & . & 8 & . & 8 & . & . & . & . \\
\hline June & . & 22 & 42 & 60 & . & . & 8 & 18 \\
\hline July & 22 & 24 & 72 & 73 & . & . & 65 & 57 \\
\hline August & 18 & 7 & 63 & 78 & . & . & 41 & 56 \\
\hline September & . & . & 30 & 20 & . & . & . & . \\
\hline \multirow[t]{2}{*}{ October } & . & . & . & . & . & . & . & . \\
\hline & \multicolumn{4}{|c|}{ mean length of increased-risk episode (ELi) } & \multicolumn{4}{|c|}{ mean length of great-risk episode (ELg) } \\
\hline April & . & . & . & 2.0 & . & . & . & . \\
\hline May & . & 8.0 & . & 8.0 & . & . & . & . \\
\hline June & . & 7.3 & 7.0 & 6.0 & . & . & 8.0 & 9.0 \\
\hline July & 7.3 & 8.0 & 6.0 & 7.3 & . & . & 9.3 & 9.5 \\
\hline August & 6.0 & 3.5 & 6.3 & 7.1 & . & . & 6.3 & 7.0 \\
\hline September & . & . & 6.0 & 6.7 & . & . & . & . \\
\hline October & . & . & . & . & . & . & . & . \\
\hline
\end{tabular}

\section{Conclusions}

The results of the research presented here confirm the more stressful bioclimatic conditions facing people doing outdoor farm work in Southern Europe, as opposed to in the conditions typical for middle latitudes (Poland). The period of the possible occurrence of a heat-stress risk is for example shorter in Central Europe than in Mediterranean (at 5 months vs. 7).

The Bulgarian bioclimate is also characterised by a large number of heat-stress hours. In the summer months, heat stress can be observed there over a total of about 175 hours. By contrast, such conditions only occur during 30-50 hours a month in Poland.

A very important feature of the Bulgarian bioclimate is the occurrence of meteorological conditions which, in the summer months, can lead to a great risk of the organism overheating in the cases 
of people working outdoors. However, in Poland situations of this kind were not registered at all at the stations studied.

The results show that, in the summer months, agricultural workers in both Bulgaria and Poland must remember to protect themselves against the risk of dehydration and overheating of the body. During hot days, workers must drink enough water, as well as cooling their organisms down periodically through time spent in the shade.

\section{References}

Adam-Poupart A., Labreche F., Smargiassi A., Duguay P., Busque M-A., Gagné C., Zayed J., 2012. Impacts des changements climatiques sur la santé et la sécurité des travailleurs. Institut de recherche Robert-Sauvé en santé et en sécurité du travail (IRSST). http://www.irsst.qc.ca/media/ documents/PubIRSST/R-733.pdf [11 September 2015].

Błażejczyk K., 2011. Mapping of UTCI on the local scale (the case of Warsaw). Prace i Studia Geograficzne WGSR UW, vol. 47, pp. 275-283.

Błażejczyk K., Baranowski J., Błażejczyk A., 2014. Heat stress and occupational health and safety - spatial and temporal differentiation. Miscellanea Geographica - Regional Studies on Development, vol. 18, 1, pp. 61-67.

Błażejczyk K., Bröde P., Fiala D., Havenith G., Holmér I., Jendritzky G., Kampmann B., Kunert A., 2010. Principles of the new Universal Thermal Climate Index (UTCI) and its application to bioclimatic research on the European scale. Miscelanea Geographica, vol. 14, pp. 91-102.

Błażejczyk K., Epstein Y., Jendritzky G., Staiger H., Tinz B., 2012. Comparison of UTCI to selected thermal indices. International Journal of Biometeorology, vol. 56, no. 3, pp. 515-535.

Błażejczyk K., Kunert A., 2006. Differentiation of the bioclimatic conditions of urban areas (the case of Poland) [in:] 6 $6^{\text {th }}$ International Conference on Urban Climate, Preprints, June 12-16 2006, Göteborg, Sweden, Göteborg University, pp. 213-216.

Błażejczyk K., Kunert A., 2011. Bioklimatyczne podstawy rekreacji i turystyki w Polsce. Warszawa: IGiPZ PAN, Monografie, no. 14, 366 pp.

Bröde P., Błażejczyk K., Fiala D., Havenith G., Holmér I., Jendritzky G., Kuklane K., Kampmann B., 2013. The Universal Thermal Climate Index UTCI Compared to Ergonomics Standards for Assessing the Thermal Environment. Industrial Health, vol. 51, no. 1, pp. 16-24.

Bröde P., Fiala D., Błażejczyk K., Holmér I., Jendritzky G., Kampmann B., Tinz B., Havenith G., 2012. Deriving the operational procedure for the Universal Thermal Climate Index (UTCI). International Journal of Biometeorology, 56, 3, pp. 481-494.

CDC, 2008. Heat-Related Deaths among Crop Workers - United States, 1992-2006. MMWR Weekly, vol. 57, no. 24, pp. 649-653.

Epstein Y., Moran D.S., 2006. Thermal comfort and heat stress indices. Industrial Health, vol. 44, pp. 388-398.

Fiala D., Havenith G., Bröde P., Kampmann B., Jendritzky G., 2012. UTCI-Fiala multi-node model of human heat transfer and temperature regulation. International Journal of Biometeorology, vol. 56, no. 3, pp. 429-441.

Heat-waves: risks and responses, 2004. Health and Global Environmental Change, Geneva: Health and Global Environmental Change, SERIES, 2, WHO. 
ISO 7243, 1989. Hot environments; estimation of the heat stress on working man, based on the WBGT-index (wet bulb globe temperature). Geneva: International Organisation for Standardization.

ISO 7933, 2004. Hot environments - analytical determination of thermal stress. Geneva: International Organisation of Standardization.

Jackson L.L., Rosenberg H.R., 2010. Preventing heat-related illness among agricultural workers. Journal of Agromedicine, vol. 15, no. 3, pp. 200-215.

Kampmann B., Bröde P., Fiala D., 2012. Physiological responses to temperature and humidity compared to the assessment by UTCI, WGBT and PHS. International Journal of Biometeorology, vol. 56, no. 3, pp. 505-513.

Kjellstrom T., Holmér I., Lemke B., 2009. Workplace heat stress, health and productivity - an increasing challenge for low- and middle-income countries during climate change. Global Health Action, 2.

Leibman A.K., Augustave W., 2010. Agricultural Health and Safety: Incorporating the Worker Perspective. Journal of Agromedicine, vol. 15, no. 3, pp. 192-199.

Masterson J., Richardson F.A., 1979. Humidex, A Method of Quantifying Human Discomfort Due to Excessive Heat and Humidity. Downsview, Ontario, Environment Canada.

Nag P.K., Nag A., 2009. Vulnerability to heat stress: Scenario in Western India. Ahmedabad, National Institute of Occupational Health. http://searo.who.int/india/topics/ occupational_health/Occupational_Health_Vulnerability_to_heat_stress_scenario_of_western_India.pdf [15 September 2015].

Parsons K., 2003. Human thermal environments. The effects of hot, moderate and cold temperatures on human health, comfort and performance. 2nd edition. London: Taylor and Francis.

Yaglou C.P., Minard D., 1957. Control of heat casualties at military training centres. American Medical Association Archives of Industrial Health, vol. 16, pp. 302-316. 
